\title{
Professor como ator do agir docente - uma análise de diários de gamificação
}

\author{
Profesor como actor del trabajo docente - un análisis de los \\ diarios de gamificación
}

\section{The teacher as actor of teaching - an analysis of journals of gamification}

\author{
Laila Alves Santos ${ }^{1}$
}

\begin{abstract}
RESUMO: Este artigo trata do trabalho docente e tem como objetivo geral verificar como o professor é representado no processo de apropriação da gamificação como instrumento, a partir de textos produzidos pelo e para o professor. Os dados utilizados para análise consistem em diários reflexivos escritos pela professora-pesquisadora e produzidos antes e após aulas que tiveram elementos da gamificação envolvidos. Baseamos nossa análise no posicionamento epistemológico do Interacionismo Sociodiscursivo (ISD) privilegiando os níveis enunciativos e semânticos da análise de elementos linguístico-discursivos. A partir do gênero diários pode-se observar o trabalho real, além das as capacidades mobilizadas para o agir, postura do professor diante dos impedimentos e o desenvolvimento dentro de uma aula desde seu planejamento, à execução e avaliação. O que nos leva a concluir que o professor, em seu trabalho real é ator do seu trabalho e agir, baseando ações em suas intenções e motivos.
\end{abstract}

PALAVRAS-CHAVE: Agir docente. Ator. Apropriação de instrumentos. Trabalho prescrito. Trabalho real.

RESUMEN: Este artículo trata del trabajo docente y tiene como objetivo general verificar cómo el profesor está representado en el proceso de apropiación de la gamificación como instrumento, a partir de textos producidos por y para el profesor. Los datos utilizados para análisis consisten en diarios reflexivos escritos por la profesora-investigadora y producidos antes y después de clases que tuvieron elementos de la gamificación involucrados. Basamos nuestro análisis en el posicionamiento epistemológico del Interaccionismo Sociodiscursivo (ISD) privilegiando los niveles enunciativos y semánticos del análisis de elementos lingüístico-discursivos. A partir del género diario se puede observar el trabajo real, además de las capacidades movilizadas para el actuar, postura del profesor frente a los impedimentos y el desarrollo dentro de una clase desde su planificación, a la ejecución y evaluación. Lo

\footnotetext{
${ }^{1}$ Mestra em Linguística Aplicada pelo Programa de Pós-graduação em Linguística Aplicada da Universidade de Taubaté (UNITAU) na área de concentração: Língua materna e Línguas estrangeiras e na linha de pesquisa da educação como trabalho.
} 
que nos lleva a concluir que el profesor, en su trabajo real es actor de su trabajo y actuar, basando acciones en sus intenciones y motivos.

PALABRAS CLAVE: Acceder al docente. Actor. Apropiación de instrumentos. Trabajo prescrito. Trabajo real.

ABSTRACT: This article concerns the teaching work and has as main objective to verify how the teacher is represented in the process of appropriation of gamification as an instrument for the teaching work. The data used for analysis consist of journals written by the teacher-researcher and produced before and after classes that had elements of gamification involved. We base our analysis on the epistemological positioning of Sociodiscursive Interactionism (ISD) focusing on the enunciative and semantic levels of the analysis of linguistic-discursive elements. From the analysis of the journals we may observe the real work of a teacher, mobilized capacities to act, the teacher's attitude towards the obstacles and the development of teaching from its planning, execution to the evaluation. Which leads us to conclude that the teacher, in her/his real work is actor of her/his work and act, basing actions on intentions and motives.

KEY-WORDS: Teaching acting. Actor. Appropriation of instruments. Prescribed work. Real work.

\section{Introdução}

Este artigo trata do trabalho docente e inscreve-se no quadro de um projeto mais amplo², tendo como objetivo geral verificar como o professor é representado no processo de apropriação da gamificação como instrumento, a partir de textos produzidos pelo e para o professor.

Esse estudo faz-se relevante, considerando que pesquisas ${ }^{3}$ revelam que documentos prescritivos oficiais direcionados a professores não atribuem ao professor o papel de ator do seu próprio trabalho.

Baseamos nossa análise no posicionamento epistemológico do Interacionismo Sociodiscursivo (ISD) e é a partir desta base que as análises do

\footnotetext{
2 "A apropriação da gamificação pelo professor como instrumento do agir docente", pesquisa vinculada ao projeto de pesquisa "Análise do trabalho do professor de línguas expresso em textos produzidos por, para e sobre esse profissional de educação", que é coordenado pela Profa. Dra. Adriana Cintra de Carvalho Pinto, no Programa de Mestrado em Linguística Aplicada, da Universidade de Taubaté (UNITAU).

3 Pesquisas da Universidade de Taubaté, coordenado pela profa. Adriana Cintra de Carvalho Pinto, como Duarte (2016), Ribeiro (2015), Abreu (2015), Barachati (2015) e Ferreira (2011).
} 
material serão conduzidas tendo Bronckart (2012) e Machado et al. (2009) como autores centrais da teoria.

Os dados utilizados na análise consistem em diários reflexivos escritos pela professora-pesquisadora e produzidos antes e após aulas que tiveram elementos da gamificação envolvidos. As aulas, de Língua Inglesa, foram ministradas pela pesquisadora em turmas de 60 e 70 anos do ensino fundamental da rede municipal da cidade de Barra Mansa, interior do Estado do Rio de Janeiro.

O corpus será analisado e interpretado tendo como objetivos específicos: compreender como o professor utiliza o instrumento e que mudanças o docente faz no instrumento (ou em si próprio) para adaptá-lo às suas necessidades; identificar se há conflitos na relação de apropriação do instrumento e se estes conflitos são resolvidos; e como o agir (ou representações do agir) do professor sofre alterações após a utilização do instrumento.

Esperamos com nossa análise dos dados responder às seguintes perguntas de pesquisa: 1) O que o professor fez para utilizar o instrumento gamificação? 2) Quais os conflitos no uso do instrumento? Eles foram resolvidos? Como? 3) Que mudanças ocorreram no instrumento para que ele fosse utilizado no ensino? 4) Que capacidades o professor precisou desenvolver para lidar com o instrumento? 5) Que mudanças o instrumento trouxe para o agir do professor?

A organização do artigo dá-se da seguinte forma: Em um primeiro momento, abordaremos brevemente o trabalho e o agir docente a partir da perspectiva da Clínica da Atividade. Em segundo lugar, trataremos o conceito de gamificação e alguns elementos envolvidos na pesquisa. Em seguida, nossa base interpretativa fundamentada no Interacionismo Sociodiscursivo (ISD) será apresentada, assim como o modelo de análise textual utilizado.

Por fim, nossos resultados e achados de pesquisas seguidos pelas conclusões. 


\section{0 trabalho e o agir docente}

Nosso entendimento da concepção de trabalho deriva de estudos da Clínica da Atividade à luz de Marx (1893/1990), que conceitua o trabalho como um agir produtivo que propicia ao agente transformar não só a atividade, mas a si mesmo e a sociedade. Isto se dá, segundo Marx, porque é no trabalho que o indivíduo atua sobre o mundo exterior e o modifica enquanto retoma suas ações e se adapta, revendo suas ações previamente planejadas. Marx também deixa claro que o trabalho é um agir essencialmente humano porque, ao contrário do trabalho animal, envolve planejamento e tomada de decisão consciente do ator/agente. Pinto (2009) reforça esta distinção (trabalho animal $X$ trabalho humano) esclarecendo que 0 trabalho de abelhas e formigas, por exemplo, não só é repetitivo e instintivo, mas também não promove desenvolvimento das capacidades dos agentes e apropriação dos instrumentos envolvidos para resolver conflitos na atividade, por mais elaborado que seja.

A Clínica da Atividade considera em seus estudos não só o trabalho realizado e o trabalho prescrito, mas também o que não é realizado, o que se deixa de fazer, além dos empecilhos para a execução de atividades do trabalhador, o que é denominado trabalho real.

Sendo assim, compreendemos por trabalho real, aquilo que se faz (atividade), mas também o que não se faz e o que não se pode fazer. Mazzillo (2006), acrescenta que a atividade real engloba também o que é mentalmente feito pelo sujeito para a realização de uma atividade. 0 que implica dizer que, 0 trabalho real não necessariamente é observável de forma direta podendo ser percebido, ou não, na ação realizada.

Pinto (2009), em harmonia com o que foi dito por Mazzillo, adiciona que para explicar o trabalho real é necessário considerar o que a autora chama de pré-ocupações do sujeito que o realiza, sendo estas da ordem do desejo, prescrição e das condições do trabalho. Pré-ocupações que, quando não 
conciliadas, trazem conflitos ao trabalhador. Os fracassos e desejos não realizados na atividade são parte do trabalho real e é a partir desta consciência dos impedimentos e não-realizações que o indivíduo se supera e se desenvolve como indivíduo e trabalhador.

Quanto ao profissional docente, especificamente, destacamos que este se guia pelos objetos construídos por si e para si na busca de alcançar os objetivos e executar as tarefas prescritas. Durante a atividade o professor: 1) Reconfigura as prescrições que lhe são determinadas antes mesmo de entrar na sala de aula e as adapta quando considera oportuno segundo suas próprias capacidades e recursos (físicos, afetivos, cognitivos, sociais, materiais etc.), objetivos e desejos, levando em consideração seu público e os critérios avaliativos das instituições; 2) Escolhe, modifica e/ou mantém seu agir dependendo da necessidade do momento; 3) Apropria-se de instrumentos que considera úteis para si e por si; 4) Escolhe o instrumento apropriado para cada situação; 5) Utiliza modelos de agir sócio historicamente construídos a partir do seu coletivo de trabalho; e 6) Soluciona, ou não, conflitos com os quais se depara, desenvolvendo suas capacidades individuais ou entrando em crise quando não encontra solução no coletivo de trabalho ou instituição (PINTO, 2009).

As múltiplas ações atribuídas ao professor, acima descritas, ocorrem no universo interacional da atividade docente, o qual foi ilustrado no esquema de Machado et al. (2009) e é exposto aqui na Figura 1: 
Figura 1 - Esquema da atividade do professor

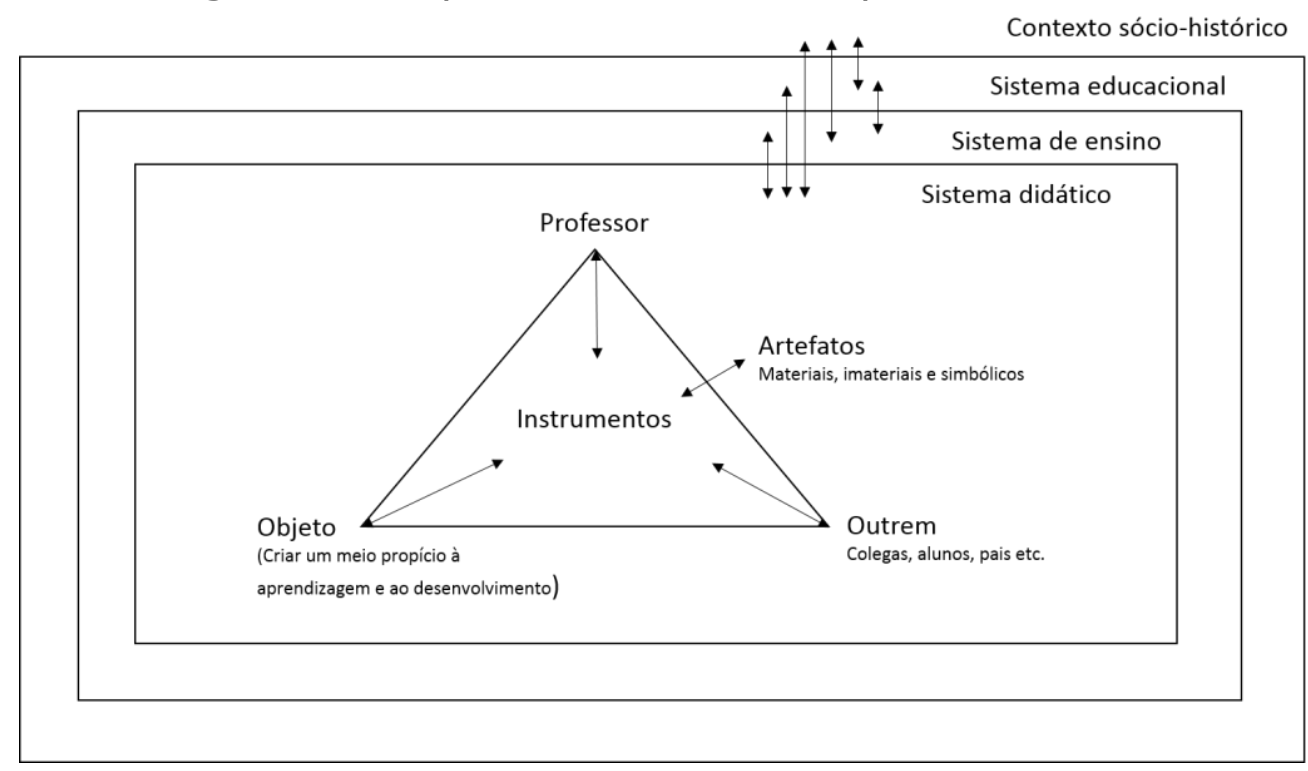

Fonte: Machado et al. (2009).

No cenário brasileiro, o Ministério da Educação (MEC) poderia ser apontado no esquema como parte do sistema educacional e tem o papel de formular diretrizes gerais em caráter prescritivo para os níveis de educação aqui determinados como sistema de ensino (educação infantil, fundamental, médio, superior). Como elementos centrais da atividade educacional encontram-se 0 professor (sujeito), o objeto (conteúdo e habilidade a serem aprendidos) e outrem, formando a tríade viva (CLOT, 2010) da atividade docente. Lados de uma relação que só pode ser intermediada e apaziguada por instrumentos. Instrumentos estes que apenas existem quando artefatos considerados úteis e eficazes para o sujeito (aqui, o professor) são apropriados por este e para este numa relação tão harmônica e íntima que tanto artefato quanto sujeito é transformado como resultado do processo da apropriação.

$\mathrm{Na}$ seção seguinte, tentaremos elucidar de forma simplificada alguns conceitos inerentes à Gamificação, visto que a professora-pesquisadora, nosso 
sujeito de pesquisa, tomou para si essa abordagem como instrumento apaziguador de alguns de seus conflitos vividos em sala de aula.

\section{Um pouco sobre o instrumento Gamificação}

É inquestionável o sucesso de jogos tecnológicos nos dias atuais. Exemplos como Pokemon Go, Minecraft, Candy Crush (entre muitos outros) deixam clara a abrangência e dedicação de jogadores de diversas idades, gêneros e classes sociais. A gamificação, por vezes confundida com o uso de jogos em si, trata da apropriação de mecanismos e elementos, dinâmicas e estética de jogos em contextos que não têm jogos como foco, objetivando a resolução de problemas, a motivação e engajamento de um público-alvo (BUSARELLO; ULBRICHT; FADEL, 2014).

Vianna et al. (2013) acrescentam que a união destes elementos é capaz de reproduzir as mesmas emoções e resultados obtidos com o ato de jogar. Vejamos alguns exemplos:

O filme A vida é bela (vencedor do Oscar de melhor filme em língua estrangeira em 1999) retrata a realidade transformada em jogo por Guido, interpretado pelo ator e diretor Roberto Benigni, que ao ser levado com seu filho para um campo de concentração nazista durante a Segunda Guerra Mundial, cria uma realidade alternativa com narrativa, pontuações, premiações e tarefas para proteger seu filho da realidade e violência da guerra;

O aplicativo WAZE une jogo a um programa de GPS. O usuário do software tem etapas de evolução de seus avatares por tempo de uso, além de integrar usuários e recompensá-los por informações inseridas no aplicativo (custos de combustíveis em postos, presença de radares, fluxo de trânsito etc.);

O desafio SEBRAE desafia universitários e simula a administração, etapas de negócio, produção e venda de produtos como em situação real; e 
Alves, Minho e Diniz (2014) relatam um jogo realizado na noite de 20 de maio de 2011 na biblioteca pública de Nova York envolvendo 500 pessoas que receberam a missão de escrever um livro em uma noite com base em pistas espalhadas pela biblioteca. $\mathrm{O}$ jogo recebeu o nome de "Find the Future" e desafiou os participantes a percorrerem a biblioteca desvendando pistas e escrevendo histórias. Como resultado, após 6 horas de jogo, um livro com 100 histórias foi criado.

Estes quatro exemplos supracitados demostram soluções lúdicas, nas quais mecanismos de jogos são inseridos para instigar a motivação para a resolução de uma tarefa pré-determinada. Dentre os vários elementos de jogos, destacamos aqui (ZICHERMANN; CUNNINGHAM, 2011):

- Pontos: mais do que promover estímulo para o jogador, a pontuação pode servir como parâmetro para que o desenvolvedor possa acompanhar os resultados dos jogadores;

- Níveis: etapas de progressão dentro do jogo, servem como controle de habilidades e conhecimentos;

- Placar (leaderboard): instrumento comparativo, consiste numa lista ordenada de nomes, dados e pontuações que promovem competição por comparação entre os jogadores;

- Divisas (badges): elementos simbólicos como distintivos que marcam objetivos e progressos. Promovem engajamento e incentivo social;

- Integração: item que nivela o jogar por sua experiência (iniciante, experiente, mestre...). Tem o intuito de cativar o jogador e engajá-lo, mantendo-o dentro do jogo. Zichermann e Cunningham (2011) apontam este elemento como 0 que mais desafia 0 designer/idealizador do jogo, porém os benefícios de se acertar neste processo garantem o engajamento a longo prazo do jogador;

- Desafios e Missões: são os objetivos claros de cada etapa do jogo. É importante considerar os perfis de jogadores e criar uma variedade de desafios para atender as expectativas do máximo de jogadores possível;

Reforçamos aqui, que muito mais há na abordagem do ensino gamificado, e que encorajamos o leitor a debruçar-se sobre as possibilidades engajadoras e motivadoras oferecidas pela gamificação. 
Seguindo com a apresentação da nossa pesquisa, e após expor o instrumento que a permeia, queremos ratificar o papel do professor na apropriação e transformação de artefatos em instrumentos úteis e eficazes na solução de problemas, papel este executado pelo professor através de escolhas e ações conscientes, o que nem sempre (ou nunca!) é reconhecido por outras partes envolvidas no esquema de trabalho do profissional docente.

\section{0 professor em textos prescritivos}

Textos prescritivos de fonte externas, como órgãos federais, estaduais e municipais têm frequentemente sido objeto de análise nos meios acadêmicos. Pesquisas revelam que o professor é, de forma generalizante, representado como agente (ou até instrumento) no processo de ensino-aprendizado. Machado e Abreu-Tardelli (2005) apontam que apesar de o professor ser responsabilizado pelo ensino (sucesso e fracasso), a ele não é dada as orientações, condições, esclarecimentos, instrumentos ou responsabilidade real expressa nas prescrições. Na mesma obra, as autoras, por meio de análises de elementos linguístico-discursivos de textos prescritos, concluem que o professor tem seu trabalho negado como se o processo de ensino-aprendizado fosse diretamente intermediado por instituições e cursos - "objetos inanimados" (MACHADO; ABREU-TARDELLI, 2005, p. 21).

Conclusões similares, sobre a representação do professor em textos prescritivos, foram reveladas por Machado e Bronckart (2005, p. 205) "[...] mesmo quando é evocado o seu agir concreto (ativo ou receptivo) em relação aos alunos, eles não são nunca postos como sendo dotados das dimensões de uma semântica da ação [...]".

Ferreira (2011) também analisa o apagamento do professor ou determinação deste como objeto ou instrumento em diretrizes e parâmetros curriculares de ensino. $\mathrm{O}$ autor aponta marcadores linguísticos que, em momentos referencia, até mesmo, o livro didático como protagonista do ensino- 
aprendizado, colocando o professor no patamar de ferramentas como tecnologia, por exemplo.

Aproximando-nos da análise dos dados e discussões de nossos resultados, na seção seguinte, abordaremos a base teórica para a interpretação dos dados da pesquisa advindos do Interacionismo Sociodiscursivo.

\section{Modelo de análise de textos}

O Interacionismo Sociodiscursivo, doravante ISD, é uma corrente fundamentada no Interacionismo Social e que busca a compreensão do desenvolvimento humano e as interações sociais a partir da interpretação da linguagem expressa em textos, sejam eles orais ou escritos.

Duarte (2016, p. 93) tece uma relação esclarecedora das linhas teóricas, que alinhadas, deram vida ao ISD:

Percebemos a sintonia de tantos teóricos e conceitos que se embasam na relação de interação com o outro: Vygotsky, pelo conceito de mediação, por meio da perspectiva sócio-histórica; Bakhtin e Círculo, pelo conceito de dialogismo e polifonia; Leontiev, por propor a atividade como uma formação coletiva; Habermas, pela visão do agir comunicativo; Ricoeur, por acreditar que são nos/pelos textos que se reconfigura o agir humano; Clot, pelo desenvolvimento e análise de métodos que buscam ajudar trabalhadores por meio da linguagem; Moreno, pela ação psicodramática que leva indivíduos em interação a trazer para fora situações acumuladas; Bronckart, pela criação de modelos de análise de textos que buscam compreender as ações humanas em interação; entre outros teóricos da Linguística, da Psicologia, da Sociologia, da Filosofia e de outras Ciências que buscam ancorar seus estudos na mesma fonte: o interacionismo social.

Ressaltamos que, em meio a tantas possibilidades de compreender o agir e as relações humanas com a corrente sócio-interacionista, a linguagem é fator congruente de todas as teorias acima mencionadas por Duarte (2016). O ISD vê na discursividade em gêneros textuais um instrumento para a tomada de 
consciência ${ }^{4}$, para o desenvolvimento psicológico e transformador, o que, por sua vez, leva à organização do próprio comportamento humano.

Entendemos, suportados por estudos de Bronckart (2012), Pinto (2009), Banks-Leite, Smolka e Anjos (2016), que após a materialização do agir pela discursividade em textos, orais ou escritos, o indivíduo pode mudar as significações antes atribuídas ao (seu) trabalho, o que conceitualmente determina a reconfiguração.

Interessa-nos apoderarmo-nos de textos escritos para e pelo próprio trabalhador em situação real de trabalho para compreendermos e avaliarmos o agir docente e suas reconfigurações, em especial acerca da distância entre trabalho prescrito e trabalho real. Isto porque para compreender o agir do professor é necessário ir além da observação. "[...] essa abordagem concebe a realidade do trabalho muito além do que é visível: o trabalho real de um ser humano seria também seu trabalho pensado, impedido, possível etc." (BRONCKART, 2008, p. 100).

Dentro deste arcabouço de dimensões inerentes do agir e presentes em textos, o ISD propõe modelos metodológicos para análises textuais que convergem para descobertas pertinentes à abordagem sócio-interacionista. Sendo assim, apresentaremos em nossa análise de dados, as análises linguístico-discursivas, do corpus, em níveis enunciativo e semântico, a partir do modelo completo indicado por Bronckart $(2012)^{5}$, sendo que no nível enunciativo analisa-se e interpreta-se as vozes e modalizações do e no texto, promovendo reflexão sobre as responsabilidades, julgamentos, opiniões e sentimentos expressos; e no nível semântico faz-se a análise das formas e elementos do agir pelo apontamento das razões, intenções e recursos no curso do agir do sujeito.

\footnotetext{
${ }^{4}$ Vygotsky aponta a palavra e o pensamento como peças-chave para a tomada de consciência. Para o autor, não há consciência sem discursividade, porque é com a linguagem que o indivíduo organiza, estrutura e compreende os conceitos. (VYGOTSKY, 2004).

${ }^{5}$ Bronckart (2012) indica para a análise de textos a necessidade do (i) levantamento das condições de produção e (ii) análise das características linguístico-discursivas em 3 níveis: organizacional, enunciativo e semântico.
} 


\section{Análise dos dados e discussão dos resultados}

Os dados da nossa pesquisa consistem em relatos extraídos de um diário reflexivo escrito por uma das professoras-pesquisadoras. Fisicamente, os textos foram produzidos, ao longo de aproximadamente 6 meses no ano de 2016, sobre a experiência de gamificar atividades para 3 turmas de $6^{\circ}$ e $7^{\circ}$ anos do ensino fundamental em uma escola da rede municipal de Barra Mansa, no interior do Estado do Rio de Janeiro.

Com o objetivo primário de reavaliar suas ações e melhorar as estratégias durante 0 uso do instrumento gamificação, a professorapesquisadora escreveu textos livres e com linguajar informal - características do diário reflexivo.

No nível enunciativo, foram analisadas a presença das marcas de pessoa e modalizações de enunciado, o que nos ajudou a identificar o estatuto individual ou coletivo de cada ação no curso do agir da professora.

No nível semântico, analisamos os elementos do agir: razões/motivos, finalidades/intenções, instrumentos/recursos; e formas do agir.

O Quadro 1 demonstra as questões de análise referentes a cada nível considerado na pesquisa:

Quadro 1 - Questões pontuais de análise

\begin{tabular}{|c|c|c|}
\hline $\begin{array}{l}\text { Nível de } \\
\text { Análise de } \\
\text { Textos }\end{array}$ & $\begin{array}{l}\text { Unidade de } \\
\text { Análise }\end{array}$ & Questões de Análise \\
\hline Enunciativo & $\begin{array}{l}\text { - Vozes } \\
\text { - Modalizações }\end{array}$ & $\begin{array}{l}\text { 1. Quais as vozes expressas, explicita ou } \\
\text { implicitamente, no texto? } \\
\text { 2. Como o professor avalia os conteúdos } \\
\text { tematizados nos textos? }\end{array}$ \\
\hline Semântico & $\begin{array}{l}\text { - Formas de agir: } \\
\text { individual e coletivo } \\
\\
\text { - Elementos do agir: } \\
\text { razões, motivos; }\end{array}$ & $\begin{array}{l}\text { 1. Quais os protagonistas do agir? } \\
\text { 2. Que problemas o professor enfrentou } \\
\text { durante o seu agir? } \\
\text { 3. O que o professor foi impedido de } \\
\text { fazer? }\end{array}$ \\
\hline
\end{tabular}




\begin{tabular}{|l|l|l|}
\hline $\begin{array}{l}\text { finalidades, } \\
\text { intenções; } \\
\text { e instrumentos, } \\
\text { recursos. }\end{array}$ & $\begin{array}{l}\text { 4. Como os problemas e impedimentos } \\
\text { foram resolvidos ou contornados? }\end{array}$ \\
\hline
\end{tabular}

Fonte: Elaborado pela autora

Bronckart (2012) indica que no nível enunciativo, a análise do texto busca compreender as entidades que assumem - ou a elas são atribuídas responsabilidade sobre o enunciado (vozes), assim como a forma pela qual estas entidades avaliam e comentam o conteúdo temático do texto (modalizações).

Partindo das três categorias gerais definidas pelo ISD: vozes de personagens, vozes de instâncias sociais e voz do autor, apontamos alguns exemplos nos quais cada categoria é identificada nos diários reflexivos:

A voz de personagem pode ser identificada no trecho abaixo, onde uma aluna ganhadora do prêmio tem sua opinião expressa pela fala da professora: D_E: [...]. Ela adorou!!!

Nos diários $\mathrm{H}$ e $\mathrm{L}$ encontram-se exemplos da voz social do grupo alunos, implicitamente referenciadas pelo autor: $\mathrm{D}_{-} \mathrm{H}$ : [...] Os alunos me cobram e sinto que vou ficar desacreditada por eles se eu deixar as recompensas para o fim do bimestre [...] / D_L: [...] Muitos me cobraram os badges para cada atividade e teste. E alguns perguntaram se a prova não seria "diferente"! [...].

Todavia, de forma geral, a voz do autor prevalece nos textos, assumindo ele a responsabilidade enunciativa e papel de personagem central dos textos. Exemplo: D_C: Entreguei para cada aluno uma cartela onde serão colados os adesivos coloridos/ D_G: Eu estou pecando em não explorar tudo o que a Gamificação tem a oferecer [...] / D_I: [...] Percebi também que este método não chamou tanto a atenção deles [...].

A comprovação da voz do autor - neste caso, o profissional docente como predominante no texto, ressalta o papel do professor como protagonista responsável pelos enunciados e ações, caracterizando-o como ator. 
Para melhor compreendermos o agir desse personagem central prosseguimos com as avaliações das modalizações ${ }^{6}$, iniciando pelas do mundo subjetivo, denominadas modalizações apreciativas, nas quais a professora aponta suas alegrias e frustrações a partir das reações e respostas dos alunos ao uso do instrumento. É a partir dessas reações que a professora planeja suas ações seguintes e reavalia as anteriores. Vejamos: D_L: Acho que eu é que fiquei mais decepcionada pelas aulas não terem "nada" de atrativo./ D_F: Fiquei muito decepcionada comigo mesmo./ D_D: Fiquei muito feliz e realizada [...] / D_I: Prejudicando tanto que eles nem conseguiram terminar a prova em uma aula. Fiasco. / D_I: Pequei mais uma vez por não ter entregue badges $[\ldots]$.

No plano das responsabilidades da entidade fonte de julgamento, expressas nas modalizações pragmáticas, identificamos pré-ocupações e responsabilidades sobre o uso e resultados do uso do instrumento: D_A: [...] mas de qualquer forma quero me antecipar./ $\mathrm{D}_{-} \mathrm{H}$ : [...] não posso deixar a empolgação dos alunos sumir.

As avaliações apoiadas em conhecimentos e critérios do mundo objetivo foram identificadas através das modalizações lógicas. Com a análise dessas modalizações podemos identificar o agir do professor sendo reavaliado e o uso do instrumento - ou o próprio instrumento - em processo de adaptação. Exemplo: D_A: Acredito que o jeito vai ser adaptar mesmo. / D_J: Acho agora que Gamificar TODOS os bimestres é exagero. / D_L: Acho que mesmo se eu tivesse programado atividades gamificadas, não conseguiria fazê-las direito.

Considerando as modalizações deônticas, cujos critérios estão apoiados em valores, opiniões do mundo social e regras de uso, notamos as autoprescrições e o que o professor gostaria de ter feito. Ressaltamos: D_F: A questão é que a essa altura o LeaderBoard já deveria estar exposto na sala / D_F: Eu devia ter começado isto na $2^{\mathrm{a}}$ aula do ano.

${ }^{6}$ Bronckart (2012, p. 330) divide as modalizações em: lógicas, deônticas, apreciativas e pragmáticas

Entretextos, Londrina, v. 18, n. 1, p. 163 -182, jan./ jun. 2018 
No nível semântico, foram levantados os elementos do agir (razões/motivos; finalidades/intenções; instrumentos/recursos). Os dados mostram o professor como protagonista e ator, ou seja, sujeito com motivos/razões, intenções/finalidades, recursos/instrumentos, que planeja, modifica e avalia suas ações. Em diários e demais textos escritos pelo próprio professor, é possível evidencia-lo como ator, não como mero utilizador de instrumentos, ao contrário do que é apontado em textos prescritivos, nos quais o professor é minimizado pelo instrumento e o instrumento é posto em posição de ator (ABREU, 2015; FERREIRA, 2011).

Vejamos alguns exemplos do professor como ator nos diários reflexivos:

1. Começar disciplina online (finalidade: melhorar o clima das aulas; motivo: motivar alunos - Cf. D_A);

2. Rascunhar os conteúdos (instrumento: matriz curricular; finalidade: adaptar conteúdo à gamificação - Cf. D_A);

3. Transformar ideias (instrumento: aplicativos e material impresso; finalidade: adaptar gamificação à realidade tecnológica dos alunos; motivo: alguns não possuem celular - Cf. D_A);

4. Montar enquete sobre uso de tecnologias e jogos (intenção: Identificar hábitos de jogos, uso de celular e internet; finalidade: Não excluir a possibilidade de utilizar celulares em sala - Cf. D_B);

5. Criar narrativa (instrumento: Questionário múltipla escolha com narrativa e mestre; intenção: Utilizar mais mecanismos da gamificação - Cf. D_G);

6. Utilizar aplicativo para criação dos avatares (instrumento: celular próprio; finalidade: imagens dos alunos representadas no placar de líderes; motivo: versões desenhadas à mão dificultariam o manuseio das imagens - Cf. D_F), e;

7. Criar prova gamificada (instrumento: circuito com etapas e sorteio de questões; finalidade: substituir formato tradicional de prova; motivo: a motivação se perdeu com o formato tradicional de prova - Cf. D_I). 
Do aspecto individual e coletivo, os diários revelam a predominância do agir individual, porém, ressaltamos o agir coletivo em, por exemplo, "Temos uma série de vídeos para assistir e artigos para ler" (Cf. D_A), onde a professora relata o seu próprio agir e de colegas do programa de mestrado também participantes da disciplina online.

Também a partir do curso do agir, nossa análise indica a existência de conflitos enfrentados antes ou durante o uso do instrumento. Para melhor apresentar nossos resultados, vejamos a Quadro 2:

Quadro 2 - Conflitos e resoluções

\begin{tabular}{|l|l|l|}
\hline \multicolumn{1}{|c|}{ Conflitos enfrentados } & \multicolumn{1}{c|}{$\begin{array}{c}\text { Há } \\
\text { resolução? }\end{array}$} & \multicolumn{1}{|c|}{$\begin{array}{c}\text { De que forma foram resolvidos ou } \\
\text { contornados? }\end{array}$} \\
\hline $\begin{array}{l}\text { Falta de informação } \\
\text { quanto à quantidade de } \\
\text { alunos que possuem } \\
\text { celular }\end{array}$ & $\begin{array}{l}\text { Criação de enquete para obter } \\
\text { informações. }\end{array}$ \\
\hline $\begin{array}{l}\text { Escola não possui internet } \\
\text { Aluna não poderia ser } \\
\text { premiada com doces }\end{array}$ & $\operatorname{Sim}$ & $\begin{array}{l}\text { Transformação de ideias de aplicativos } \\
\text { para material impresso }\end{array}$ \\
\hline $\begin{array}{l}\text { Dificuldade no manuseio } \\
\text { de avatares criados à mão }\end{array}$ & $\operatorname{Sim}$ & $\begin{array}{l}\text { Utilização de aplicativo para criação de } \\
\text { avatares }\end{array}$ \\
\hline $\begin{array}{l}\text { Falta de narrativa, } \\
\text { elemento inerente à } \\
\text { gamificação }\end{array}$ & $\operatorname{Sim}$ & $\begin{array}{l}\text { Formulação de narrativa em } \\
\text { questionário com inclusão de monstro } \\
\text { como personagem do desafio }\end{array}$ \\
\hline $\begin{array}{l}\text { Falta de tempo para colar } \\
\text { adesivos }\end{array}$ & $\operatorname{Sim}$ & $\begin{array}{l}\text { Mudança no método de controle de } \\
\text { pontuações }\end{array}$ \\
\hline $\begin{array}{l}\text { Prova em moldes } \\
\text { tradicionais desmotivou o } \\
\text { jogo }\end{array}$ & $\operatorname{Sim}$ & $\begin{array}{l}\text { Criação de prova em formato de } \\
\text { circuito, em grupos e incluindo sorteio } \\
\text { de questões }\end{array}$ \\
\hline $\begin{array}{l}\text { Preocupação com excesso } \\
\text { de uso do instrumento. }\end{array}$ & $\operatorname{Sim}$ & Encerramento da gamificação \\
\hline
\end{tabular}

Fonte: Elaborado pela autora.

Em sua prática docente no curso da utilização do instrumento, a professora contorna os conflitos acima reportados, com a criação de recursos 
alternativos para que o instrumento possa continuar sendo utilizado. Todavia, há impedimentos expressos e não resolvidos. Identificamos:

(1) Elevado número de alunos por turma: Diários F, H e I;

(2) Falta de tempo/ calendário apertado: Diários $\mathrm{F}, \mathrm{H}(4 \mathrm{x})$, I e L (3x).

(3) Falta de familiaridade com 0 instrumento pela professora: Diários $F(4 x), G(3 x), H, I, J(2 x)$.

Como dito anteriormente, o indivíduo se transforma e transforma seu agir quando conflitos são resolvidos, mas a não resolução desses pode causar adoecimento, e até, abandono da atividade. No caso da professora em questão, a opção feita, após meses de utilização do instrumento e em face da reincidência de conflitos não resolvidos, foi a interrupção no uso do instrumento e reflexão sobre possíveis estratégias a serem tomadas quando em outro momento esse instrumento for utilizado, visando assim, transpor esses empecilhos não resolvidos.

\section{Conclusão}

A partir de diários escritos por uma professora, foi possível ver o curso do agir para a apropriação do instrumento gamificação, as capacidades mobilizadas para essa apropriação, reações dos alunos, postura do professor diante dessas reações e o desenvolvimento dentro de uma aula desde seu planejamento, à execução e avaliação.

Esta pesquisa se deu a partir da curiosidade investigativa acerca do uso do instrumento gamificação, mas a questão geral proposta por nosso estudo tenta compreender como o professor é representado durante o processo de apropriação desse instrumento.

Concluímos que, a partir da análise de um texto autoprescritivo, o professor transforma o instrumento de acordo com as suas intenções, 
motivações, capacidades e condições de trabalho, sendo ele, portanto, protagonista e ator do processo de apropriação.

No decorrer do uso de um instrumento - neste caso, a gamificação - é demandado ao profissional conhecimento do instrumento e de sua aplicação no contexto escolar, múltiplas capacidades internas para lidar com os vários impedimentos enfrentados no decorrer do uso, dinamismo e dedicação para adaptar o instrumento à realidade do público-alvo e estruturas oferecidas pela escola.

Acerca dos impedimentos, estes são muitos e desafiadores. A não resolução deles pode trazer prejuízos à saúde emocional e física do professor. No entanto, o professor mostrou a capacidade de resolver maior parte deles apoiando-se em suas capacidades internas e reflexão das suas ações como verdadeiro responsável pelo seu agir docente.

É nossa esperança que este estudo possa estimular novas pesquisas que tratam o professor como profissional ator do seu agir, repleto de intenções, motivos e capacidades, sem o qual a atividade não passa de uma sequência estática de palavras, normas e prescrições sem ator que as dê vida.

\section{Referências}

ABREU, Maria Lúcia Florenzano Vidal Gonçalves. O trabalho docente interpretado em um manual de instrução ao professor sobre a educação digital. 2015. Dissertação (Mestrado em Linguística Aplicada) - Universidade de Taubaté, Taubaté, 2015.

ALVES, Lynn Rosalina Gama; MINHO, Marcelle Rose da Silva; DINIZ, Marcelo Vera Cruz. Gamificação: diálogos com a educação. In: FADEL, Luciane Maria et al. (Org.). Gamificação na educação. São Paulo: Pimenta Cultural, 2014. p. 7497.

BANKS-LEITE, Luci; SMOLKA, Ana Luiza Bustamante; ANJOS, Daniela Dias dos (Org.). Diálogos na perspectiva histórico-cultural: interlocuções com a Clínica da Atividade. Campinas: Mercado de Letras, 2016. 
BARACHATI, Gisele Maria Souza. O ensino da escrita representado em textos produzidos por professores após um processo de formação continuada. 2015. 186 f. Dissertação (Mestrado em Linguística Aplicada) - Universidade de Taubaté, Taubaté, 2015.

BRONCKART, Jean-Paul. Atividade de linguagem, textos e discursos: por um interacionismo sociodiscursivo. 2. ed. São Paulo: EDUC, 2012.

BRONCKART, Jean-Paul. O agir nos discursos: das concepções teóricas às concepções dos trabalhadores. Tradução: Anna Rachel Machado; Maria de Lourdes Meirelles Matêncio. Campinas: Mercado das Letras, 2008.

BUSARELLO, Raul Inácio; ULBRICHT, Vania Ribas; FADEL, Luciane Maria. A gamificação e a sistemática de jogo: conceitos sobre a gamificação como recurso motivacional. In: FADEL, Luciane Maria et al. (Org.). Gamificação na educação. São Paulo: Pimenta Cultural, 2014. p. 11-37.

CLOT, Yves. Trabalho e poder do agir. Belo Horizonte: Fabrefactum, 2010.

DUARTE, Ewerton Batista. O ensino de Língua Inglesa revelado no dizer do professor de Ensino Médio de uma escola paulista. 2016. Dissertação (Mestrado em Linguística Aplicada) - Universidade de Taubaté, Taubaté, 2016.

FERREIRA, Geraldo Generoso. O trabalho docente representado em textos prescritivos: uma análise dos conteúdos básicos comuns de língua estrangeira do estado de Minas Gerais. 2011. 103 f. Dissertação (Mestrado em Linguística Aplicada) - Universidade de Taubaté, Taubaté, 2011.

MACHADO, Anna Rachel et al. Relações entre linguagem e trabalho educacional: novas perspectivas e métodos no quadro do interacionismo sociodiscursivo. In: ABREU-TARDELLI, Lilia Santos; CRISTOVÃO, Vera Lúcia Lopes (Org.). Linguagem e educação: o trabalho do professor em uma nova perspectiva. São Paulo: Mercado de Letras, 2009. p. 15-29.

MACHADO, Anna Rachel; ABREU-TARDELLI, Lilia Santos. Textos prescritivos da educação presencial e a distância: fonte primeira do estresse do professor? Signum, Londrina, v. 8, n. 1, p. 11-24, jun. 2005.

MACHADO, Anna Rachel; BRONCKART, Jean-Paul. De que modo os textos oficiais prescrevem o trabalho do professor? Análise comparativa de documentos brasileiros e genebrianos. Delta, São Paulo, v. 21, n. 2, p. 183-214, 2005.

MARX 1990 falta referência

MAZZILLO, Tania Maria da Frota Mattos. O trabalho do professor de língua estrageira representado e avaliado em diários de aprendizagem. 2006. 173 p. 
Tese (Doutorado em Linguística Aplicada e Estudos de Linguagem) - Pontifícia Universidade Católica de São Paulo, São Paulo, 2006.

PINTO, Adriana Cintra de Carvalho. Trabalho docente (re)velado no dizer do professor de ensino fundamental. 2009. $154 \mathrm{f}$. Tese (Doutorado em Linguística Aplicada e Estudos de Linguagem) - Pontifícia Universidade Católica de São Paulo, São Paulo, 2009.

RIBEIRO, Rosângela Aparecida. O trabalho docente interpretado no dizer de uma professora do/no campo. 2015. Dissertação (Mestrado em Linguística Aplicada) - Universidade de Taubaté, Taubaté, 2015.

VIANNA, Maurício et al. Gamification, Inc: como reinventar empresas a partir de jogos. Rio de Janeiro: MJV Press, 2013.

ZICHERMANN, Gabe; CUNNINGHAM, Christopher. Gamification by design: implementing game mechanics in web and mobile apps. Sebastopol: O'Reilly Media, 2011.

VYGOTSKY, 2004 falta referência 